\title{
Numerical Study of Convective Heat Transfer on the Power Law Fluid over a Vertical Exponentially Stretching Cylinder
}

\author{
M. Naseer ${ }^{1, ~ *, ~ M . ~ Y . ~ M a l i k ~}{ }^{1}$, Abdul Rehman ${ }^{2}$ \\ ${ }^{1}$ Department of Mathematics, Quaid-i-Azam University, Islamabad, Pakistan \\ ${ }^{2}$ Department of Mathematics, University of Balochistan, Quetta, Pakistan
}

Email address:

naseermaths@yahoo.com (M. Naseer),drmymalik@hotmail.com (M. Y. Malik), rehman_maths@hotmail.com (A. Rehman)

\section{To cite this article:}

M. Naseer, M. Y. Malik, Abdul Rehman. Numerical Study of Convective Heat Transfer on the Power Law Fluid over a Vertical Exponentially Stretching Cylinder. Applied and Computational Mathematics. Vol. 4, No. 5, 2015, pp. 346-350. doi: 10.11648/j.acm.20150405.13

\begin{abstract}
The present paper is the study of boundary layer flow and heat transfer of Power law fluid flowing over a vertical exponentially stretching cylinder along its axial direction. The governing partial differential equations and the associated boundary conditions are reduced to nonlinear ordinary differential equations after using the boundary layer approximation and similarity transformations. The obtained system of nonlinear ordinary differential equations subject to the boundary conditions is solved numerically with the help of Fehlberg method. The effects of Power law index $n$, Reynolds number Re, Prandtl number $\operatorname{Pr}$, the natural convection parameter $\lambda$ and local Reynolds number $\operatorname{Re}_{a}$ are presented through graphs. The skin friction coefficient and Nusselt number are presented through tables for different parameters.
\end{abstract}

Keywords: Boundary Layer Flow, Exponential Stretching, Vertical Cylinder, Power Law Fluid, Natural Convection Heat Transfer, Fehlberg Method

\section{Introduction}

Large amount of work has been done on laminar boundary layer flow over stretching sheet. For example in extursion processes such as polymer extursion from a dye and wire driling, drawing, tunning and annealing of copper wires, the cooling of a metalic plate in a cooling bath and so on. Crane (1970) was the first who studied the stretching sheet problem. After Crane many researchers have extended this work (D. R. Jeng at al.,1986; F. Labropulu at al.,2010; E. Magyari and B. Keller, 1999; R.Ellahi, 2009; M. Y. Malik at al., 2013). The above mentioned studies are about linear stretching but in many practical situations involves non linear stretching such as exponential stretching. Many authors vary velocity of sheet exponentially with distance from slit. Elbasbesh (2001) was the first who studied the exponentially stretching sheet problem. He take a perforated sheet and notice the effect of wall mass suction on the flow and heat transfer over an exponentially stretching surface using similarity transformation.

Later on, Sanjayan and Khan $(2005,2006)$ extended the work on exponential stretching. They studied a similar kind of problem considering viscoelastic fluid model under viscousdissipation effects. The non-Newtonian fluids are very useful in industrial and engineering applications. Schowalter (1960) studied the applications of boundary layer using power law fluid. Similarity solutions for non

Newtonian power law fluids were obtained by Kapur and Srivastave (1963) and Lee et al. (1966). The power law fluids over a continous moving flat plate with constant surface velocity and temperature distribution was given by Fox et al. (1969). Anderson and Dandapat (1991) extended the pioneery work of Crane (1970) for a non-Newtonian power law fluids. Later on Hassnain (1998) extended the work for heat transfer analysis. Abel et al. (2009) studied the power law fluid over a vertical stretching sheet with variable thermal conductivity and non uniform heat source. Few relavent intresting works concerning the stretching flowes are cited in (S. Nadeem et al., 2009; Abdul Rehman et al.,2013;M.Naseer et al.,2014; C.Y.Wang and Z Angew, 1989; A. Ishak et al., 2008; I.A. Hassanien et al., 1998; S. Nadeem and Anwar Hussain, 2010; A. Ishak et al., 2011; C. Y. Wang, 2012; Abdul Rehman et $a l ., 2013 ;$;). In this paper we have studied the flow and heat transfer of a power law fluid over a vertical exponentially stretching cylinder. 


\section{Formulation}

Consider the problem of natural convection boundary layer flow of a power law fluid flowing over a vertical circular cylinder of radius $a$. The cylinder is assumed to be stretched exponentially along the axial direction with velocity $U_{w}$. The temperature at the surface of the cylinder is assumed to be $T_{w}$ and the uniform ambient temperature is taken as $T_{\infty}$ such that the quantity $T_{w}-T_{\infty}>0$ in case of the assisting flow, while $T_{w}-T_{\infty}<0$ in case of the opposing flow, respectively. Under these assumptions the boundary layer equations of motion and heat transfer are

$$
\begin{gathered}
u_{r}+\frac{u}{r}+w_{z}=0, \\
u w_{r}+w w_{z}=\frac{k}{\rho}\left(\frac{w_{r}^{n}}{r}+n w_{r}^{n-1} w_{r r}\right)+g \beta\left(T-T_{\infty}\right), \\
u T_{r}+w T_{z}=\alpha\left(T_{r r}+\frac{1}{r} T_{r}\right),
\end{gathered}
$$

where the velocity components along the $(r, z)$ axes are $(u, w), \rho$ is fluid density, $k$ is the consistency coefficient, $p$ is pressure, $g$ is the gravitational acceleration along the $z-$ direction, $\beta$ is the coefficient of thermal expansion, $T$ is the temperature, $\alpha$ is the thermal diffusibility. The corresponding boundary conditions for the problem are

$$
\begin{gathered}
u(a, z)=0, \quad w(a, z)=U_{w} \quad w(r, z) \rightarrow 0 \text { as } r \rightarrow \infty, \\
T(a, z)=T_{w}(z), \quad T(r, z) \rightarrow T_{\infty} \text { as } r \rightarrow \infty,
\end{gathered}
$$

where $U_{w}=2 a k e^{z / a}$ is the fluid velocity at the surface of the cylinder.

\section{Solution of the Problem}

Introduce the following similarity transformations:

$$
\begin{aligned}
& u=-\frac{1}{2} U_{w} \frac{f(\eta)}{\sqrt{\eta}}, \quad w=U_{w} f^{\prime}(\eta), \\
& \theta=\frac{T-T_{\infty}}{T_{w}-T_{\infty}}, \quad \eta=\frac{r^{2}}{a^{2}}
\end{aligned}
$$

Where the characteristic temperature difference is calculated from the relations $T_{w}-T_{\infty}=c e^{z / a}$. With the help of transformations (6) and (7), Eqs. (1) to (3) take the form

$$
\begin{aligned}
& (n+1) \eta^{\frac{n-1}{2}}\left(f^{\prime \prime}\right)^{n}+2 n \eta^{\frac{n+1}{2}} f^{\prime \prime \prime}\left(f^{\prime \prime}\right)^{n-1} \\
& +\operatorname{Re}_{a}\left(f f^{\prime \prime}-f^{\prime 2}\right)+\operatorname{Re}_{a} \lambda \theta=0
\end{aligned}
$$

$$
\eta \theta^{\prime \prime}+\theta^{\prime}+\frac{1}{2} \operatorname{Re} \operatorname{Pr}\left(f \theta^{\prime}-f^{\prime} \theta\right)=0
$$

In which $\lambda=g \beta a\left(T_{w}-T_{\infty}\right) / U_{w}^{2}$ is the natural convection parameter, $\operatorname{Pr}=k / \rho \alpha$ is the Prandtl number, $\mathrm{Re}_{a}=\rho a^{n} U_{w}^{2-n} / k$ is the local Reynolds number and $\operatorname{Re}=a \rho U_{w} / 4 k$ is the Reynolds number. The boundary conditions in non dimensional form become

$$
\begin{gathered}
f(1)=0, f^{\prime}(1)=1, \quad f^{\prime} \rightarrow 0, \text { as } \eta \rightarrow \infty, \\
\theta(1)=1, \quad \theta \rightarrow 0, \text { as } \eta \rightarrow \infty .
\end{gathered}
$$

The important physical quantities such as the shear stress at the surface $\tau_{w}$, the skin friction coefficient $c_{f}$, the heat flux at the surface of the cylinder $q_{w}$ and the local Nusselt number $\mathrm{Nu}$ are

$$
\begin{gathered}
\tau_{w}=\left.\tau_{r z}\right|_{r=a}, \quad q_{w}=-\left.k \tau_{r}\right|_{r=a}, \\
c_{f}=\frac{\tau_{w}}{\rho U_{w}^{2}}, \quad N u_{z}=\frac{a e^{z / a} q_{w}}{k\left(T_{w}-T_{\infty}\right)}
\end{gathered}
$$

The solution of the present problem is obtained by using Fehlberg Method.

\section{Results and Discussion}

The problem of natural convection boundary layer flow of a Power law fluid over an exponentially stretched cylinder is studied in this paper. The cylinder is assumed to be stretched exponentially along its axial direction. The exponential stretching velocity at the surface of the cylinder is assumed to be $U_{w}=2 a k e^{z / a}$. The solution of the problem is obtained numerically with the help of Fehlberg Method. The effect of the various parameters such as the Reynolds number Re, the local Reynolds number $\operatorname{Re}_{a}$, the power law index $n$, the Prandtl number $\operatorname{Pr}$ and the natural convection parameter $\lambda$ over the non dimensional velocity and temperature profiles are presented graphically and in the form of tables. Fig.1 shows the effects of natural convection parameter $\lambda$ on the velocity profile $f^{\prime}$ when $n=1$. From Fig. 1 it is observed that by increasing the values of natural convection parameter $\lambda$ the velocity profile increases. Fig.2 Shows the influence of local Reynolds number $\operatorname{Re}_{a}$ over the velocity profile $f^{\prime}$ when $n=1$. From Fig.2 it is clear that by increasing the values of local Reynolds number $\mathrm{Re}_{a}$ the velocity profile $f^{\prime}$ decreases. Figs.3 and 4 shows the effects of Prandtl number $\operatorname{Pr}$ and Reynolds number $\mathrm{Re}$ on temperature profile $\theta$ when $n=1$. Similar characteristics are observed for Prandtl number $\operatorname{Pr}$ and Reynolds number Re in Figs.3 and 4 , by increasing the values of these numbers temperature profile decreases. Fig.5 shows the effects of natural 
convection parameter $\lambda$ on the velocity profile $f^{\prime}$ when $n=2$. The velocity profile $f^{\prime}$ decreases by increasing the values of natural convection parameter $\lambda$. Fig.6 shows opposite behavior of velocity profile $f^{\prime}$ when $n=2$, the velocity profile increases by increasing local Reynolds number $\mathrm{Re}_{a}$. In Figs.7 and 8 temperature profiles are presented for $n=2$. The temperature profiles behave just like for $n=1$. Table 1 shows the boundary derivatives for the velocity profile at the surface of the cylinder that corresponds to the skin friction coefficient at the surface tabulated for different values of $\lambda$ and $\operatorname{Re}_{a}$. From the Table 1 it is observed that the magnitude of the boundary derivative increases with increase in both $\lambda$ and $\mathrm{Re}_{a}$. Table 2 shows the values for local Nusselt numbers calculated for different values of $\operatorname{Re}$ and $\operatorname{Pr}$.From entries in the Table 2 it is noticed that with increase in both $\mathrm{Re}$ and $\mathrm{Pr}$, the Local Nusselt number $N u$ decreases.

Table 1. [- $\left.f^{\prime \prime}(1)\right]$ skin friction coefficient at the surface.

\begin{tabular}{llllll}
\hline $\boldsymbol{\lambda} \backslash \mathbf{R e}_{\mathbf{a}}$ & $\mathbf{0}$ & $\mathbf{0 . 1}$ & $\mathbf{0 . 2}$ & $\mathbf{0 . 3}$ & $\mathbf{0 . 4}$ \\
\hline 1 & 0.9859 & 0.9903 & 0.9953 & 1.0011 & 1.0078 \\
3 & 1.2212 & 1.2366 & 1.2544 & 1.2754 & 1.3012 \\
5 & 1.4494 & 1.4755 & 1.5065 & 1.5452 & 1.5972 \\
10 & 1.9274 & 1.9809 & 2.0499 & 2.1505 & 2.3941 \\
15 & 2.3145 & 2.3968 & 2.5121 & 2.7246 & 2.9537 \\
\hline
\end{tabular}

Table 2. [- $\left.\theta^{\prime}(1)\right]$ local Nusselt numbers.

\begin{tabular}{llllll}
\hline $\operatorname{Pr} \backslash \mathbf{R e}$ & $\mathbf{0}$ & $\mathbf{0 . 1}$ & $\mathbf{0 . 2}$ & $\mathbf{0 . 3}$ & $\mathbf{0 . 4}$ \\
\hline 1 & 1.1971 & 1.1967 & 1.1962 & 1.1957 & 1.1952 \\
7 & 1.7912 & 1.7890 & 1.7866 & 1.7838 & 1.7808 \\
10 & 3.5901 & 3.5808 & 3.5699 & 3.5566 & 3.5396 \\
15 & 5.5503 & 5.5360 & 5.5182 & 5.4944 & 5.4580 \\
25 & 6.6652 & 6.6491 & 6.6285 & 6.5999 & 6.5508 \\
\hline
\end{tabular}

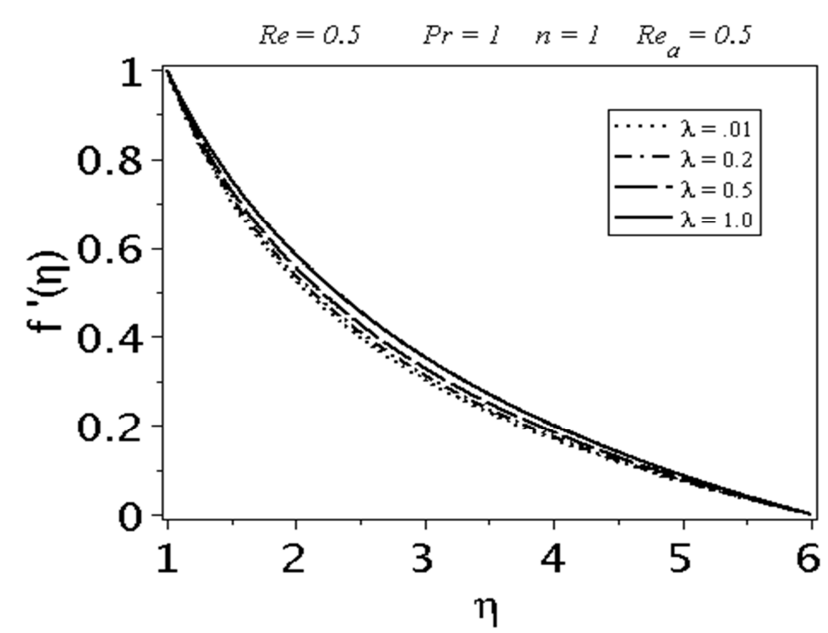

Fig. 1. The influence of natural convection parameter on velocity profile.

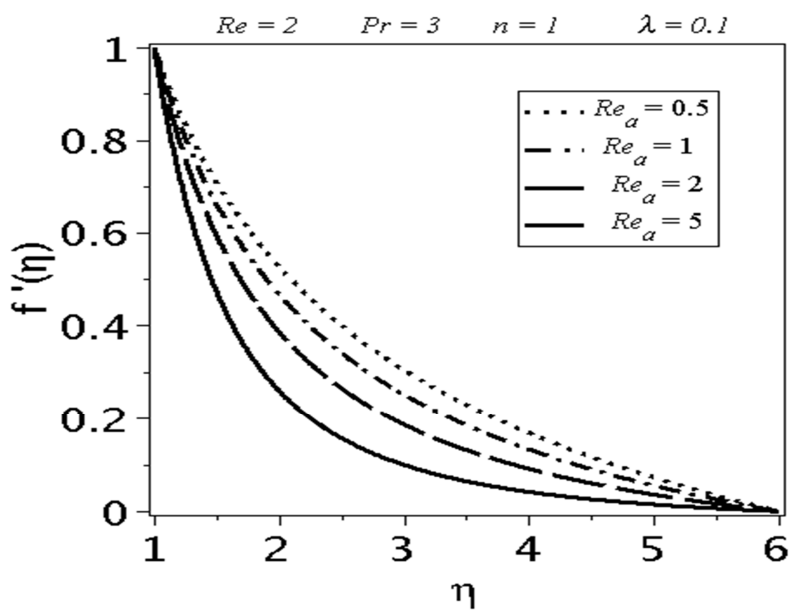

Fig. 2. The influence of local Reynolds number on velocity profile.

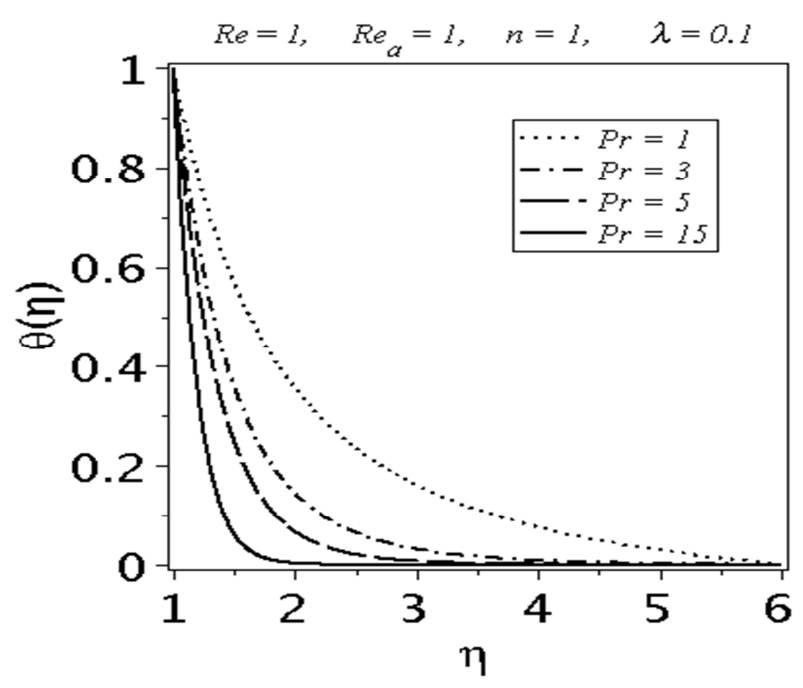

Fig. 3. The influence of Prandtl number on temperature profile.

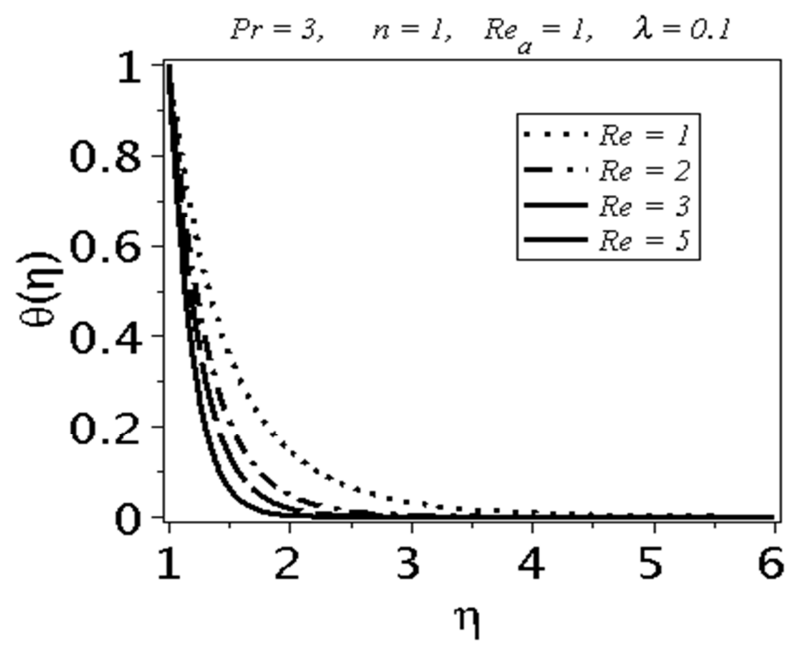

Fig. 4. The influence of Reynolds number on temperature profile. 


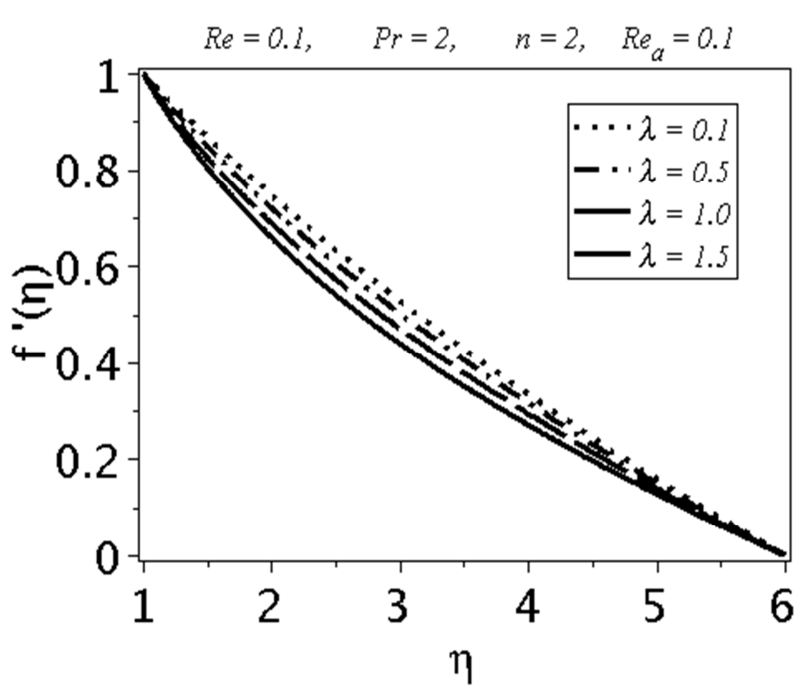

Fig. 5. The influence of natural convection parameter on velocity profile.

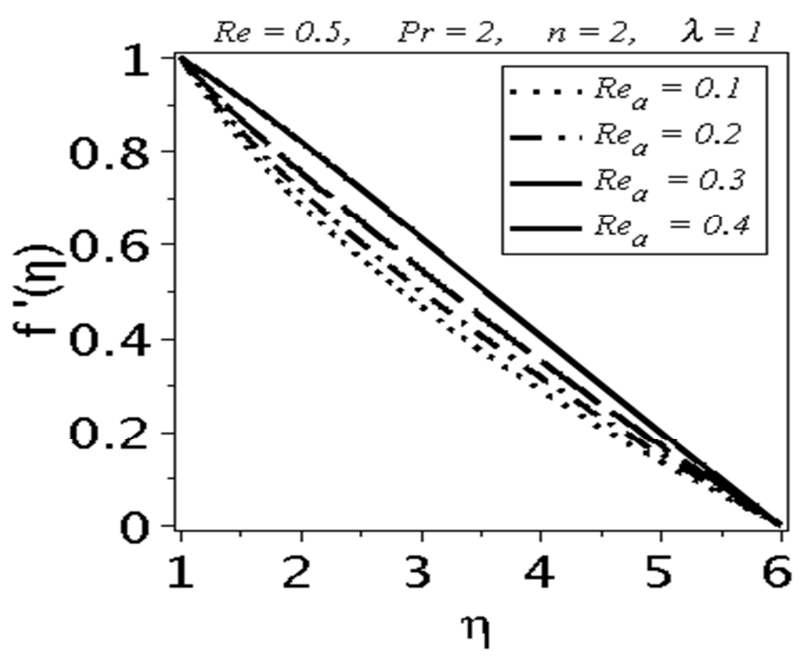

Fig. 6. The influence of local Reynolds number on velocity profile.

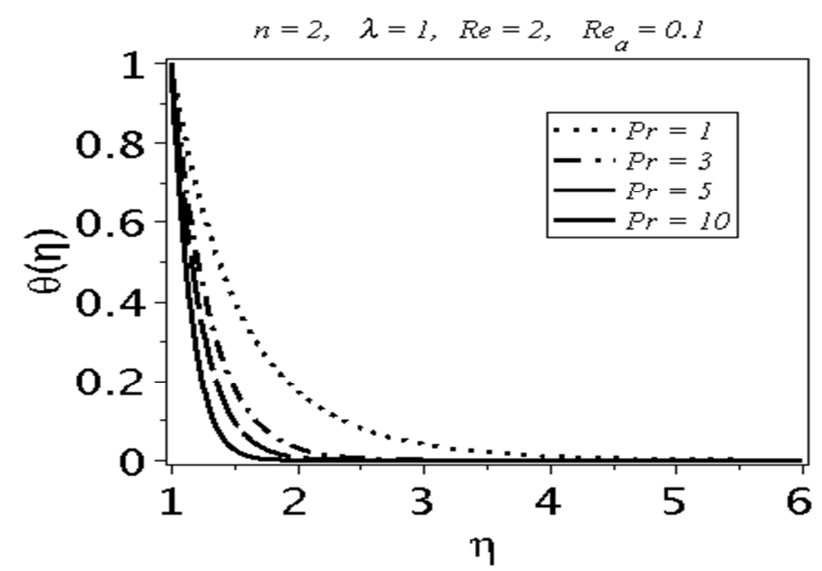

Fig. 7. The influence of Prandtl number on temperature profile.

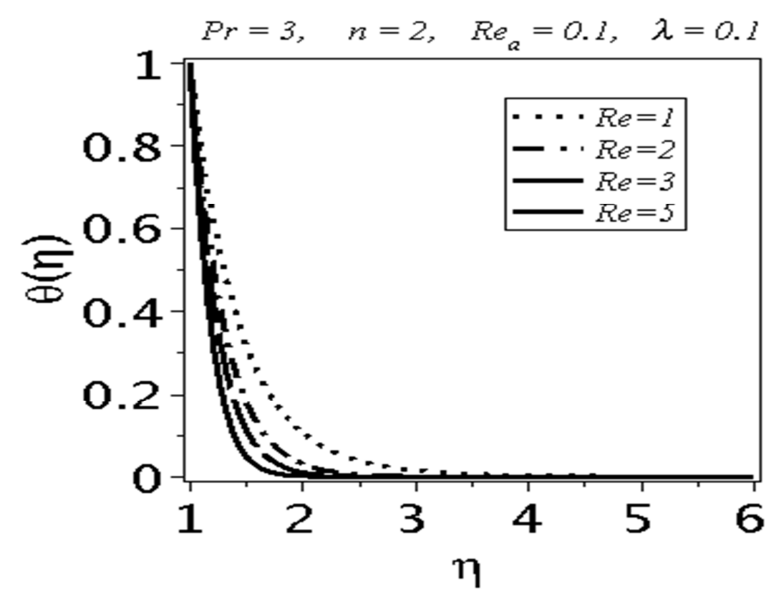

Fig. 8. The influence of Reynolds number on temperature profile.

\section{References}

[1] L.J. Crane (1970), Flow past a stretching plate, ZAMP 21 645-647.

[2] D. R. Jeng, T. C. A. Chang and K. Dewitt (1986), ASME J. Heat Transfer 108 532-539.

[3] F. Labropulu, D. Li and I. Pop , (2010)., Non-orthogonal stagnation-point flow towards a stretching surface in a non-Newtonian fluid with heat transfer, Int. J. of Ther. Sci. 49 $1042-1050$.

[4] E. Magyari and B. Keller (1999), Heat and mass transfer in the boundary layers on an exponentially stretching continuous surface, J PHYS D, 32 (5) 577-585

[5] R.Ellahi, (2009), Comm. Nonl. Sci. Num. Simu., 14 $1377-1384$.

[6] M. Y. Malik, M. Naseer, S. Nadeem and Abdul Rehman, (2013), Appl Nanosci. DOI 10.1007/s13204-013-0267-0

[7] Elbashbeshy and E.M.A, (2001), Arch. Mech. 53 (6) 643-651.

[8] E.Sanjayanand and S.K.Khan, (2005), Int.J.Heat Mass Transfer 48 1534-1542

[9] E.Sanjayanand and S.K.Khan, (2006), Int. J. Therm.Sci. 45 819-828.

[10] W. R. Schowlter (1960), A.I.Ch.E.J. 6 24-28

[11] J. N. Kapur and R. C. Srivastave (1963), ZAMP 14 383-388

[12] S. Y. Lee and W. F. Ames (1966), A.I.Ch.E.J. 12 700-708

[13] V. G. Fox, L. E. Erickson and L. T. Fan (1969), A.I.Ch.E.J. 14 726-736

[14] H. I. Anderson and B. S. Dandapat (1991), Appl. Anal. Continuous Media 1 339-347

[15] I. A. Hassanien, A. A. Abdullah, R. S. R. Gorla (1989), Math. Comput. Model. 28 105-116

[16] M. S. Abel, P. S. Datti and N. Mahesha (2009), Int. J. Heat Mass Transfer 52 2902-2913

[17] S. Nadeem, S. Abbasbandy and M. Hussain (2009), Z Naturforch. 64a 575-582 
[18] M. Naseer, M. Y. Malik, S. Nadeem, Abdul Rehman (2014), The boundary layer flow of hyperbolic tangent fluid over a vertical exponentially stretching cylinder, Alex.Eng. Jour. 53(3) $747-750$

[19] Abdul Rehman, S. Nadeem and M. Y. Malik (2013), J Power Tech 93(2) 122-132

[20] C.Y.Wang (1989), Z Angew Math Mech 69 418-420

[21] A. Ishak, R. Nazar and I. Pop (2008), App. Math. Mod. 32 2059-2066

[22] I.A. Hassanien, A.A. Abdullah and R.S.R. Gorla (1998), Math. Comput. Model. 28 105-116
[23] S. Nadeem and Anwar Hussain (2010), Zeitschrift fur Naturforschung. 65a 1-9

[24] A.Ishak, R. Nazar and I. Pop (2011), Int J Nonlinear Mech 46 1017-1021

[25] C. Y. Wang (2012), Commun. Nonlinear Sci. Numer. Simulat, 17 1098-1103.

[26] Abdul Rehman, S.Nadeem, S.Iqbal, M.Y.Malik,and M.Naseer, (2013), Proc IMechE Part N : J Nanoengineering and Nanosystems, DOI: 10.1177/1740349913517872 